\title{
INFLUENCE OF PORTEVIN-LE CHATELIER EFFECT ON RUPTURE MODE OF ALLOY 718 SPECIMENS
}

\author{
V.Garat $^{1}$, J-M.Cloue ${ }^{1}$, B.Viguier ${ }^{2}$, E.Andrieu ${ }^{2}$ \\ ${ }^{1}$ Framatome ANP Fuel Division; 10, rue J.Récamier; 69456 Lyon Cedex, France \\ ${ }^{2}$ CIRIMAT ; UMR CNRS 5085 ; 118, route de Narbonne, 31077 Toulouse Cedex 04, France
}

Keywords: Jerky flow, Intergranular fracture, Oxidation

\begin{abstract}
A set of tensile tests has been carried out under air environment in the temperature range $\left[450^{\circ} \mathrm{C}\right.$ $700^{\circ} \mathrm{C}$ ] in order to characterize the interactions between oxidation assisted intergranular cracking and Portevin - Le Chatelier effect. It is shown that the occurrence of jerky flow stops the intergranular damaging mechanism. The construction of a Dynamic strain aging-Intergranular fracture-PLC instabilities map is then proposed. The surprising relation between crack initiation disappearance and PLC instabilities of type $\mathrm{C}$ in the temperature range explored is discussed. Finally the assumption of the occurrence of such phenomenon at the tip of a propagating crack is addressed.
\end{abstract}

\section{Introduction}

Jerky flow also known as Portevin-Le Chatelier effect has been first shown on Al-Cu alloys [1] and, afterwards, has been studied intensively in other dilute metallic alloys especially in steels, aluminium and nickel based alloys [2-5]. Physical processes involved in this type of flow instability as well as the associated localization of the deformation have been modeled and simulated [6-8]. Recent improvements of measuring techniques for deformation fields [9] offer the possibility to check those simulations under several aspects (localization, spatial coupling between bands, bands width). Nevertheless, a few studies are dealing with the role of grain boundaries on PLC plastic instabilities [10-12] and consequently, there is a lack of knowledge on the effect of this phenomenon on the evolution of intergranular internal stresses. An interesting way to study this particular point can be found in the scientific field dealing with oxidation assisted intergranular cracking (OAIC) because, in most of the cases, this damaging process requires to operate an intergranular oxidation process together with a high level of intergranular internal stresses. Fournier et al [13] have clearly shown that the occurrence of PLC instabilities in alloy 718 during slow strain rate tests at $400^{\circ} \mathrm{C}$ stops immediately the intergranular crack propagation.

The aims of the present paper are firstly, to bring new experimental results completing at higher temperature the work undertaken by Fournier et al and then, to evaluate the interactions between crack initiation and localization of plastic instabilities. As strain rate controlled tensile tests have been carried out on thin strip, both crack initiation and propagation sensitivity to dynamic strain aging (DSA) have been investigated.

\section{Materials and Experimental Procedure}

The material used in this study was obtained through a double melting process: vacuum induction melting plus vacuum arc remelting. The nominal composition of the alloy is given in Table 1. The cast ingot was hot and cold rolled down to a thickness of $1 \mathrm{~mm}$, followed by a solution annealing heat treatment at $1000^{\circ} \mathrm{C}$ for one hour ended by air quenching. 
Table 1. Chemical composition of the alloy 718 strip (wt \%)

\begin{tabular}{|c|c|c|c|c|c|c|}
\hline Ni & $\mathbf{C r}$ & $\mathbf{M o}$ & $\mathbf{F e}$ & $\mathbf{T i}$ & $\mathbf{A l}$ & $\mathbf{N b}+\mathbf{T a}$ \\
\hline bal & 18.1 & 2.88 & 18.3 & 1.04 & 0.54 & 5.15 \\
\hline
\end{tabular}

Tensile specimens (Figure 1) were then electro-discharge machined and heat treated under vacuum following the usual heat treatment: $720^{\circ} \mathrm{C} / 8 \mathrm{~h}$ then cooling $50^{\circ} \mathrm{C} / \mathrm{h}$ down to $620^{\circ} \mathrm{C}$ with a $8 \mathrm{~h}$ hold time. Figure 2 shows the final microstructure of the material i.e. fully recrystallised and free from delta phase precipitates. Primary carbides alignments are often observed and sometimes suspected to serve as crack initiation sites. Finally, samples were thinned by mechanical grinding down to $0.3 \mathrm{~mm}$ all along the gauge length and mechanically polished by using $\mathrm{SiC}$ paper and diamond paste down to the grade $1 \mu \mathrm{m}$. This thinning process aimed at increasing the damaging effects of environment through a reduction of the ratio volume/surface. Mechanical tests were performed with an electro-mechanical tensile machine under displacement rate controlled. A laser extensometer was used to measure the deformation of the specimens. Heating was ensured by a three zone radiation furnace which allows to control precisely $\left( \pm 1^{\circ} \mathrm{C}\right)$ the temperature all along the gauge length in the considered temperature range $\left(20-700^{\circ} \mathrm{C}\right)$. Tests were performed under laboratory air and, when necessary, the oxygen partial pressure was decreased by means of a vacuum device and /or hydrogenated argon $\left(5 \% \mathrm{H}_{2}\right)$. Fractured samples were observed by SEM (LEO 435 VP).



Figure 1. Tensile thin specimen (thickness $=0.3 \mathrm{~mm}$ )



Figure 2. Microstructure of thin strip material, after etching - SEM 


\section{Experimental Results}

\section{Effect of Environment}

In order to evaluate the specific role of oxidation on the occurrence of intergranular fracture in the dynamic strain aging domain, several tests were performed at $650^{\circ} \mathrm{C}-10^{-3} \mathrm{~s}^{-1}$ either under laboratory air or under hydrogenated argon. As initially expected, the fracture surface was fully transgranular ductile under hydrogenated argon while intergranular brittle fracture areas as well as intergranular cracks all along the gauge length were observed on specimens tested under air environment (see Figure 3). The global mechanical response of these flat and smooth specimens indicates that the material of the study is sensitive both to oxidation assisted crack initiation and propagation.

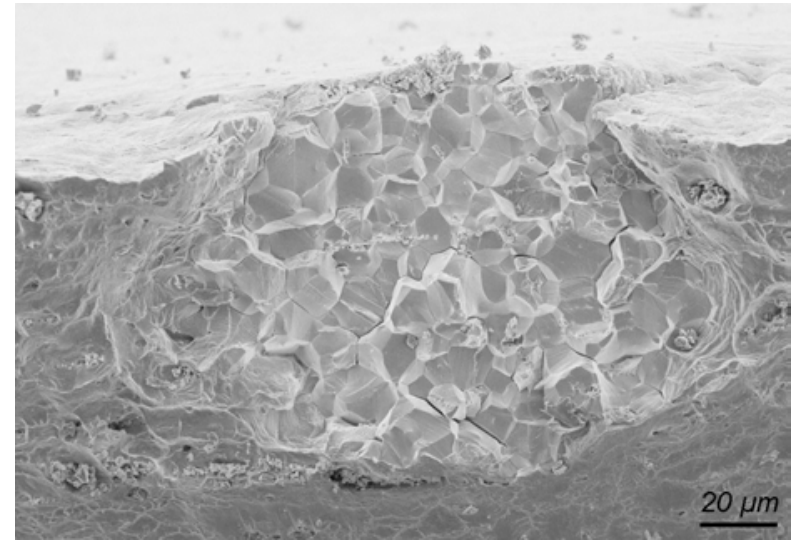

a) In air: fragile intergranular areas

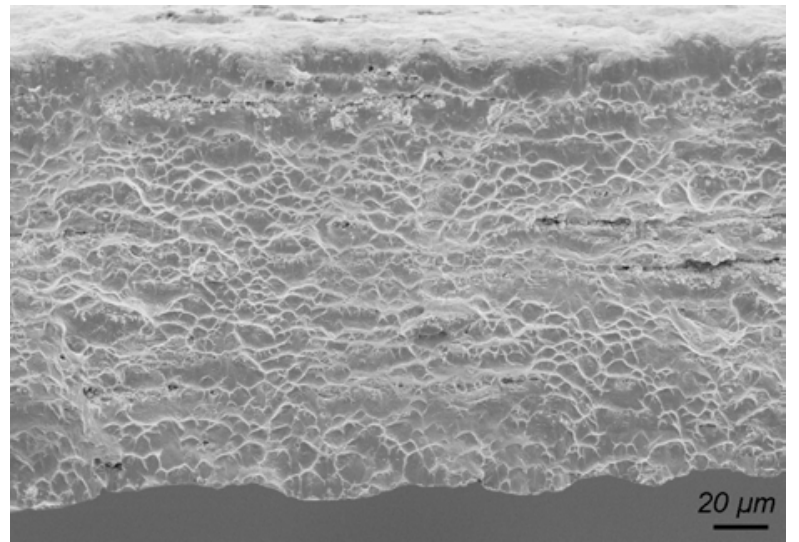

b) In Ar- $\mathrm{H}_{2}$ : transgranular ductile

Figure 3. Rupture paths - SEM

\section{Characterization of PLC Types}

As a matter of example, Figure 4 shows the type of serration on the stress-strain curve recorded when PLC occurred in the explored temperature-strain rate domain. The amplitude of the serrations is rather regular close to $100 \mathrm{MPa}$ together with the emission of an audible characteristic noise. On this figure, one can also notice that, in the same testing conditions a curve without serration was obtained. This experimental result is simply due to the fact that the mechanical testing conditions are close to the threshold of PLC occurrence. The comparison of the two types of mechanical response indicates that the flow stress without serrations is slightly greater. The strain to rupture seems to follow the same trend when OAIC is not active. Otherwise intergranular fracture occurs and the stress and strain to fracture are markedly reduced. When dealing with the type of serration, all the recorded experimental curves seem to indicate that serrations are of type $\mathrm{C}$ which are known to be associated with a random nucleation of deformation bands all along the specimen length. An unambiguous characterization will require specific equipments in order to follow, at high temperature, the local strains along nearly the whole specimen quasi-instantaneously. 


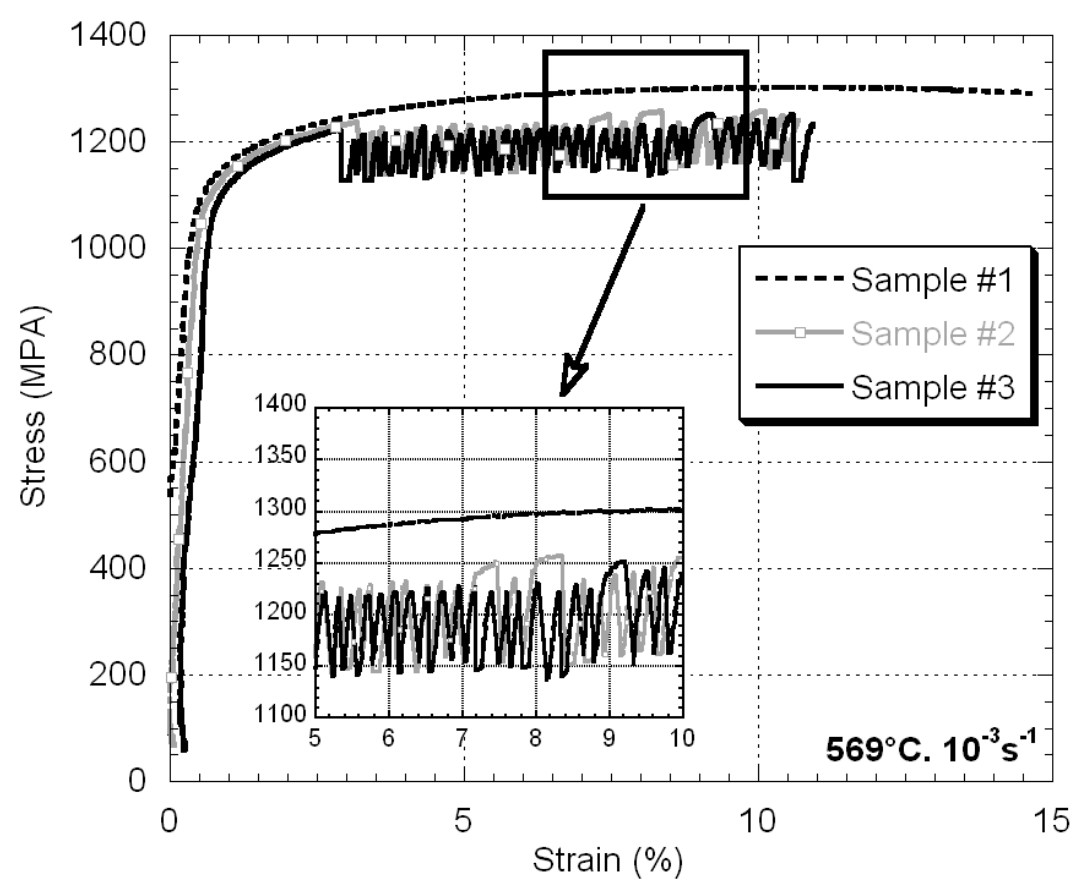

Figure 4. Stress-strain curves at $569^{\circ} \mathrm{C}$ and $10^{-3} \mathrm{~s}^{-1}$

\section{Experimental Construction of a DSA-Fracture Mode-PLC Map}

In the temperature range $\left[450^{\circ} \mathrm{C}-700^{\circ} \mathrm{C}\right]$, various tensile tests were carried out under air testing conditions at different strain rates. The results obtained both in term of flow modes and fracture mode are presented in Figure 5 together with the results obtained previously by Fournier et al [13]. Rupture paths observed by SEM show systematically that above $450^{\circ} \mathrm{C}$ the fracture is transgranular ductile when PLC triggers off whereas an intergranular brittle mode of fracture is observed in the other cases. This experimental fact is so systematic that a border can be drawn which separates both smooth from serrated plastic flow and intergranular fracture from transgranular ductile.

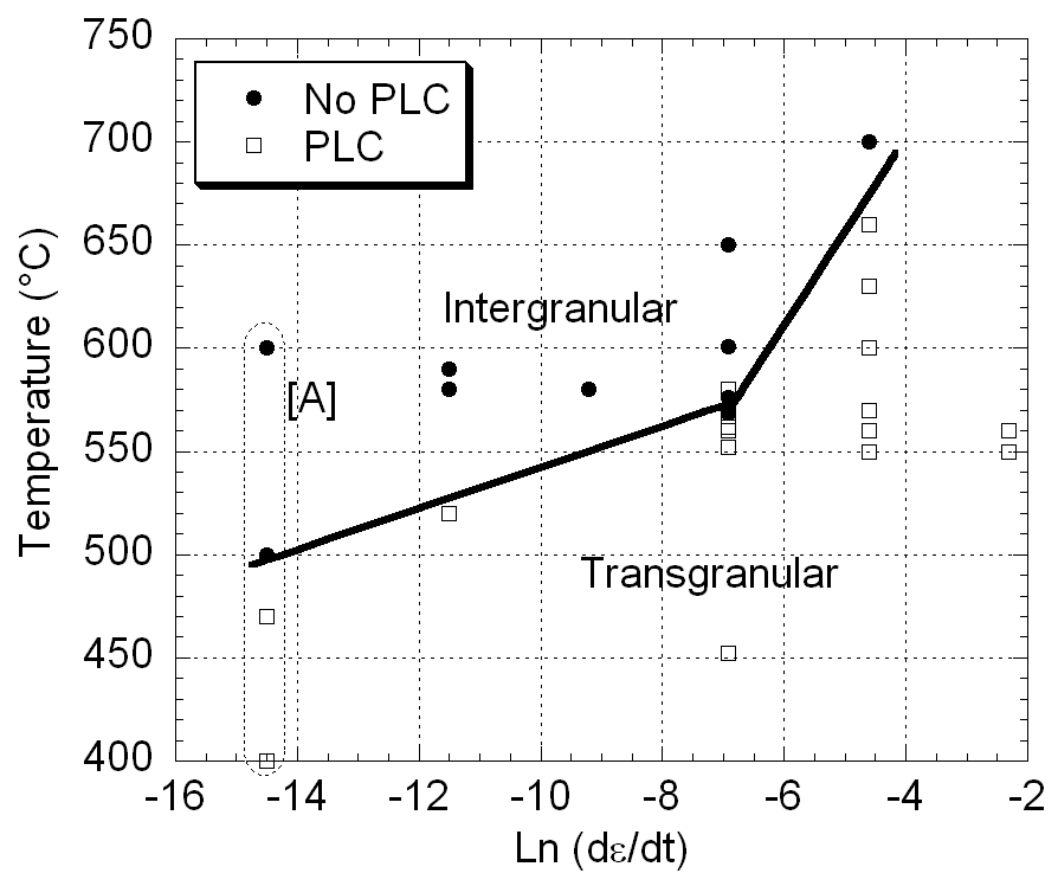

Figure 5. Rupture modes and plastic flow modes map. [A]: data from Fournier [13] 
It is worth mentioning here that when the testing mechanical conditions are located in the left part of the map, any thermo-mechanical modification that initiates PLC instabilities will stop the intergranular damaging process. Complementary mechanical tests were performed and are still in progress to verify this last point. Temperature drop $\left(25^{\circ} \mathrm{C}\right)$ or 2 unloading cycles with an amplitude of $200 \mathrm{MPa}$ at $600^{\circ} \mathrm{C}$ can initiate PLC instabilities and stop OAIC.

\section{Discussion}

Several questions have to be addressed in the following part:

- Is there an effect of the oxidation kinetic to explain the existence of the border?

- Is there a role of the serration in terms of repeated unloading on the sensitivity to OAIC?

- Does the randomness of type $\mathrm{C}$ instabilities compatible with crack initiation process?

- Is there a relation between this phenomena and the creep crack growth rate limitation at high temperature?

From the set of curves presented in Figure 4, it is clear that for the three testing conditions the oxidation kinetic is similar for the three specimens while fracture modes are so different. Moreover, before being mechanically tested, the specimens are hold $10 \mathrm{mn}$ at least at the testing temperature. Thus, the assumption according to which, in this temperature range, the oxidation rate is fast enough to be considered as a non-limiting parameter in the global damaging process seems to be valid. However, the validity of this assumption has to be reconsidered when dealing with a lower temperature range.

A large number of studies have been devoted to the effect of unloading or overloading on fatigue crack growth. Creep-fatigue crack growth rate in alloy 718 and more particularly in N18 alloy is known to be markedly reduced when an unloading of at least $5 \%$ is applied at the beginning of the hold time period [14]. This unloading sequence generates a compression zone at the crack tip which stops the OAIC damaging process. Thus, assuming that a crack initiates when the local propagation conditions are met i.e no compression at the crack tip at least, a possible effect of repeated unloadings on the crack initiation has to be considered. In order to try to clarify this point, two different tests were performed under air environment.

- During a constant strain rate test $\left(10^{-3} \mathrm{~s}^{-1}\right)$ at $650^{\circ} \mathrm{C}$, unloading-loading cycles with an amplitude equal to $200 \mathrm{MPa}$ were superimposed. With these testing conditions, PLC instabilities do not initiate and finally the fracture surface exhibits intergranular fracture areas.

- At $560^{\circ} \mathrm{C}$, with a constant stress rate $(1.5 \mathrm{MPa} / \mathrm{s})$, plastic deformation bands propagate during the test. Finally the fracture surface is fully ductile even if the macroscopic unloading serrations are avoid. Due to the fact that these testing conditions were chosen close to the threshold of occurrence of PLC effect at this temperature, it was then possible to get in the same testing conditions a mechanical response without instability. In this latter case, the fracture surface exhibits intergranular fracture areas.

From these complementary tests it seems that serrations, seen as repeated sequences of global unloading of the specimen, are not responsible for the disappearance of the intergranular fracture mode.

The third point to be addressed deals with the surprising relation between crack initiation and PLC initiation. The randomness of these two phenomena is often assumed. The results presented in this study suggest that these phenomena are linked in terms of initiation site. When intergranular crack initiation is possible, SEM observations all along the gauge length show that the location of the intergranular crack initiation sites is not related to primary carbide alignments but randomly distributed on the whole specimen surface. In aluminum alloys by using a laser scanning extensometer [15] it is possible to characterize the strain localization and amplitude 
simultaneously all along the specimen. When type $\mathrm{C}$ instabilities occurs it seems that randomly distributed local strain jumps are observed. Assuming that these local strain jumps allow to release internal intergranular stresses it is then possible to link them to the crack initiation sites. This way of explaining the results obtained in the present study could be improved by a careful characterization of the polycrystal by EBSD together with a numerical simulation of the mechanical behavior of the associated numerical polycrystal in order to identify "numerically" the highly stressed microstructural sites.

Finally, the last point to be addressed is the possible relation between crack growth rate upper limit and local initiation of PLC instabilities. At first, it is important to recall that the creep crack growth rate at high temperature under air environment in alloy 718 is much more rapid than under inert gas environment. So, supposing that the creep law remains unaffected by the different consequences of the oxidation process, this acceleration can't be explained by the cumulative creep damage alone. A mechanism involving oxidation assisted intergranular fracture is then rather well admitted to explain this type of phenomenon. Thus, assuming that the plastic zone moving rate is equal to the crack growth rate, it is possible, at least at $650^{\circ} \mathrm{C}$, to give a rough estimation of the maximum average local strain rate $\left(10^{-2} \mathrm{~s}^{-1}\right)$ with $\mathrm{K}=20 \mathrm{MPa} \cdot \mathrm{m}^{1 / 2}$, $\mathrm{R}_{\mathrm{p}}=50 \mu \mathrm{m}$ and $\mathrm{da} / \mathrm{dt}=10 \mathrm{~mm} / \mathrm{h}$. In the present case, this result is surprisingly close to the border reported on the map figure 3. Moreover, as the plastic zone size expands when the stress intensity factor increases, the upper limit of the crack growth rate might be raised as it is observed during high temperature crack propagation tests. Specific tests have been undertaken to explore further more this type of reasoning.

\section{Conclusions}

The present investigation into the interactions between oxidation assisted intergranular cracking (OAIC), dynamic strain aging and PLC instabilities has shown that in a rather large temperature range, the occurrence of PLC instabilities inhibits OAIC. The PLC bands have been identified as type $\mathrm{C}$ bands. As there is a striking relation between serration occurrence and the disappearance of intergranular crack initiation sites, it is proposed that the nucleation sites of strain jumps are located in the same areas in the polycrystal. This result demonstrates indirectly the randomness of these two phenomena. The question of the applicability of this phenomenon at the tip of a propagating crack to explain the upper limit of the creep crack growth rate has been addressed. Further studies are needed to better understand this surprising effect which coupled microstructure-dislocation dynamic and oxidation mechanism.

\section{Acknowledgements}

The authors are grateful to several students from ENSIACET namely S.Robert, B.Meunier, M.Campo and L.Crayssac who have performed most of the tensile tests and SEM observations and would like to thank Framatome-ANP Company for its financial support.

\section{References}

1. A.Portevin and F.Le Chatelier, C R Acad Sci Paris. 176 (1923), 507-510

2. R.A. Mulford and U.F Kocks, "New observations on the mechanisms of dynamic strain aging and of jerky flow", Acta metall. 27 (1979), 1125-1134

3. L.P.Kubin and Y.Estrin, "Dynamic strain aging and the mechanical response of alloys", Journal of physics III (1991), 929-943 
4. C.L. Hale et al., "Activation energy calculations for discontinuous yielding of Inconel 718SPF”, Mater. Sci. Eng. A 300 (2001), 153-164

5. J.P Balik et al., "Inverse critical strains for jerky flow in Al-Mg alloys", Scripta Mater. 42 (2000), 465-471

6. A.H. Cottrell. Dislocations and plastic flow in crystals. London: Oxford University Press, 1953.

7. J.Friedel. Dislocations. Oxford: Pergamon Press, 1964

8. L.P.Kubin et al., in:F.R.N. Nabarro, M.S. Duesberry (Eds.), Dislocations in solids, vol. 11, Elsevier, Amsterdam, 2002,p. 101-192

9. H.Neuhäuser et al., "on the PLC effect in strain-rate and stress-rate controlled testsstudies by laser scanning extensometry", J. All. Comp. 378 (2004), 13-18

10. H.M.Zbib and E.C.Aifantis, "On the localization and postlocalization behavior of plastic deformation. I. on the initiation of shear bands", Res. Mechan. 23 (1988), 261

11. A.Kalk et al., "Dynamic strain ageing and the boundaries of stable plastic deformation in Cu-Mn single crystals", Phil. Mag. A 72 (1995), 1239

12. Zs. Kovacs et al., "Effect of grain boundaries on PLC plastic instabilities" J. Eng. Mat. Tech. 124 (2002), 23

13. L.Fournier et al., "Oxidation induced Intergranular cracking and Portevin-Le Chatelier effect in nickel base superalloys" Mater. Sci. Eng. A 316 (2001), 166-173

14. E.Andrieu and A.Pineau, "Study of coupled phenomena involved in the oxidation assisted intergranular cracking of $\mathrm{Ni}$ based superalloys" Journal de Physique IV, vol.9, n9 (1999), 3-11

15. A.Ziegenbein et al., "Correlation of temporal instabilities and spatial localization during Portevin-Le Chatelier deformation of $\mathrm{Cu}-10$ at.\%Al and $\mathrm{Cu}-15$ at.\%Al”, Comput. Mat. Sci. 19 (2000), 27-34 